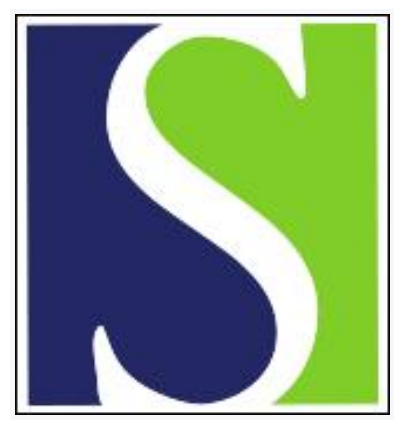

Scand J Work Environ Health 1993;19(5):360-363

https://doi.org/10.5271/sjweh.1461

Issue date: 01 Oct 1993

Meeting of the IARC working group on beryllium, cadmium, mercury and exposures in the glass manufacturing industry.

This article in PubMed: www.ncbi.nlm.nih.gov/pubmed/8296187 


\section{Meeting of the IARC working group on beryllium, cadmium, mercury and exposures in the glass manufacturing industry}

A working group of experts in chemical carcinogenesis (list of participants at the end of this article) met in Lyon, France, on 9-16 February 1993 to discuss the carcinogenic risks to humans from exposure to the metals beryllium, cadmium, and mercury and their compounds and of exposures in the glass manufacturing industries, where lead, arsenic, and other metal oxides can occur. Several observers, including representatives from Eurométaux (European Association for Metals), the International Council on Metals and the Environment, and the Primary Glass Manufacturers' Confederation, also attended the meeting. The results of the discussions will be published as volume 58 of the IARC Monographs on the Evaluation of Carcinogenic Risks to Humans.

\section{Beryllium and beryllium compounds}

Beryllium is lighter than aluminum and more rigid than steel, and it has excellent electrical and thermal conductivity. These properties have led to the production and use of the metal itself, its alloys, and its oxide in a variety of applications. The major drawback to the widespread use of beryllium metal is its brittleness.

Beryllium compounds were used extensively inthe past as phosphors in fluorescent lighting tubes. Beryllium and its compounds have since become important in solid-state computer and communication systems and in the aircraft, aerospace, and military industries. Beryllium is used as a structural material in nuclear facilities since it does not absorb thermal neutrons from the fission of nuclear fuel as other metals do; instead it reduces the energy of neutrons and reflects them back into the fission zone.

Although a relatively small number of workers has been exposed to high levels of this element, mainly in the refining and machining of the metal and in the production of its alloys or compounds, growing numbers of workers in the aircraft, aerospace, electronics and nuclear industries are potentially exposed to lower levels. The most important source of beryllium in the environment is the combustion of coal, and it has been found at levels of about $100 \mathrm{mg} \cdot \mathrm{kg}^{-1}$ in coal ash. Measures have been taken over the last 40 years to reduce such exposures, and low permissible exposure limits have been enforced in several countries. In 1952, the Beryllium Case Registry was established in the United States to collect data on the epidemiology, diagnosis, clinical features, course, and complications of acute be- ryllium-induced pneumonitis or chronic systemic beryllium diseases.

Beryllium and beryllium compounds have been evaluated by previous working groups convened by the International Agency for Research on Cancer (IARC). The reevaluation by the present group with regard to the carcinogenicity of beryllium and its compounds in humans was based on extended analyses of mortality among cohorts of workers in beryllium production plants. The consistent, marginally significant excess of deaths from lung cancer observed in an early series of cohort studies of workers at two facilities for the extraction, production, and fabrication of beryllium in the United States was confirmed by the finding of a small but significant excess of mortality from lung cancer among some 9000 workers in seven beryllium plants in the United States. The follow-up of deaths among workers entered at the Beryllium Case Registry also showed excess mortality from lung cancer, especially among those who were entered at the Registry because of acute beryllium pneumonitis. The working group concluded that the following aspects of these two recent studies support the conclusion that the work environment of people involved in refining, machining, and producing beryllium metal and alloys was causally associated with an increased risk for lung cancer: the large number of cases of cancer at that site; the consistency of the excess of that cancer; the greater excess among workers who had been hired before 1950, when the concentrations of beryllium in the workplace were relatively uncontrolled and much higher than subsequently; the fact that the highest risk for lung cancer was found in the plant from which the greatest proportion of cases of acute beryllium pneumonitis was reported to the Beryllium Case Registry; the greater risk for lung cancer in the Registry cohort, particularly among those with acute beryllium pneumonitis, who had the most intense exposure to beryllium; and the fact that the highest risks for lung cancer occurred in plants where the risk for nonmalignant respiratory diseases was the highest. Smoking was addressed in several ways in both studies and was considered not to explain the increased risk for lung cancer.

Aspects of the studies that were considered to limit their interpretation were the absence of any measurements of individual exposures to beryllium, the relatively low excess risk for lung cancer, and the absence of any mention of exposure to other lung carcinogens in the workplace (although there was no evidence that any were present). 
Other data considered to be relevant to the evaluation of the working group were the finding of increased levels of beryllium in the lungs of people who had been exposed up to 20 years previously and the fact that beryl ore, beryllium metal, several alloys of beryllium, and beryllium oxide, hydroxide and salts produced lung tumors in rats after exposure by inhalation or intratracheal instillation. The commonality of this target site suggests a common mechanism for the carcinogenesis of beryllium in humans and experimental animals. The pathogenesis of chronic beryllium lung disease involves cellmediated immunological reactions, and susceptibility varies between individuals. A similar disease is seen in exposed animals.

The overall evaluation of the working group is that beryllium and beryllium compounds are carcinogenic to humans (group 1 in the IARC classification).

\section{Cadmium and cadmium compounds}

Cadmium and its compounds had also been evaluated earlier within the IARC monographs program, but the availability of new epidemiologic and experimental data prompted a reevaluation. Cadmium, a by-product of zinc production, has been used to a significant extent only in the last $40-50$ years. Occupational exposure to cadmium and cadmium compounds can occur in smelting and refining, in cadmium alloy production, in the manufacture of nickel-cadmium batteries, through the production and use of cadmium pigments, and in electroplating. Cadmium can also occur in air, water, and food from pollution of the environment by this element, and acidification of cadmium-containing soils and sediments can increase the levels of cadmium in surface waters and crops. Several episodes of poisoning have been reported among populations eating food grown on contaminated soil, perhaps the best known being the epidemic of itai-itai disease in Japan. Cigarettes are another source of cadmium, and it has been estimated that a pack-a-day smoker accumulates $0.5 \mathrm{mg}$ of cadmium in one year.

The first indication of the possible carcinogenicity of cadmium was a report of prostatic cancers occurring in a small group of workers who had been employed before 1965 in a plant where nickel-cadmium batteries were manufactured in the United Kingdom. Conflicting results have been obtained subsequently with regard to cancer at that site. In contrast, both early and recent studies provide consistent evidence that the risk for lung cancer is increased among workers exposed to cadmium. In a study from the United States, a dose-response relationship was demonstrated between estimated cumulative exposure to cadmium and risk for lung cancer. In addition, in a large cohort of workers from 17 cadmium-processing plants in the United Kingdom, the rate of mortality from lung cancer was increased and there were suggested trends with dura- tion of employment and with intensity of exposure. Confounding by cigarette smoking was addressed directly in only one study, which did not find smoking to be a likely explanation of the result. Other studies provided analyses based on internal comparisons, which are not likely to be affected by such confounding. Control of confounding due to concomitant exposure to other metals, such as arsenic and nickel, was limited. However, analyses in which an attempt was made to distinguish cadmium-exposed workers with different levels of exposure to arsenic indicated that the increase in risk for lung cancer was unlikely to be due to exposure to arsenic.

The working group identified the following constraints that limited assessment of the studies: the numbers of long-term, highly exposed workers were small, historical data on exposure to cadmium are limited, particularly for plants outside the United States, and the ability to define a gradient of cumulative exposure varies.

The working group also took into consideration the fact that cadmium compounds induce lung tumors in experimental animals exposed by inhalation or intratracheal instillation. Ionic cadmium has genotoxic effects in a variety of eukaryotic cells, including those from humans. In addition, in studies of exposed populations in which significant responses were observed, chromosome aberrations tended to occur in the more heavily exposed groups and were of more complex types.

The overall evaluation was therefore that cadmium and cadmium compounds are carcinogenic to humans (group 1 in the IARC classification).

\section{Mercury and mercury compounds}

Inorganic mercury and organomercury compounds were evaluated for their carcinogenicity to humans on the basis of reports that these compounds induce tumors in mouse kidney. Human beings can be exposed to metallic mercury from many sources, including dental amalgam, work in mercury mining, chloralkali electrolysis, alkaline battery plants, and the manufacture of devices for measuring temperature and pressure, and they are exposed to mercury compounds through their use as fungicides in paints and on seeds and grains. Populations have been exposed to methylmercury compounds by eating contaminated fish - perhaps the most famous episode is that which caused Minamata disease in Japan or bread made from treated seed intended for sowing, as occurred in Iraq in the early 1970s.

The working group restricted its review of epidemiologic studies to those specific to metallic mercury and mercury compounds and to groups of people known to have considerable exposure. Thus, in a cohort study in a nuclear weapons factory in the United States, the mortality of men who had been exposed to metallic mercury during lithium production was followed. No difference in the risk of dying 
from lung cancer was seen between exposed and unexposed groups in the same factory, and the risk for cancers of the central nervous system was not associated with estimated levels of exposure to mercury in a nested case-referent study in two nuclear facilities. Although increased risks for cancer of the lung were observed in cohort studies of chloralkali workers in both Sweden and Norway, asbestos and tobacco smoking were considered by the authors to be the main determinants of the increases in risk. The risk for lung cancer among individuals with silicosis was found to be higher for those who had worked in mercury mines than for those who had worked elsewhere. However, few cases were involved. A case-referent study in Italy indicated an excess risk for lung cancer among women who had had heavy exposure to mercury (but also to arsenic), while manufacturing felt hats, and a population-based casereferent study in Canada showed an increased risk for lung cancer in association with exposure to metallic mercury. A report of excess risk for brain tumors among dental personnel in Sweden was not corroborated by studies in the United States and Australia.

Studies in Minamata, Japan, on the causes of death in populations with a high prevalence of methylmercury poisoning showed excess mortality from cancers of the liver and esophagus in the area of highest exposure. However, the risks for chronic liver diseases and cirrhosis were also increased, and the consumption of alcoholic beverages was known to be high in that area. A number of Swedish studies of people exposed to mercury-based seed dressings showed no significant increase in risk for cancers of the brain or soft tissues or lymphoma.

The evidence for the carcinogenicity of mercuric chloride in experimental animals was considered to be limited, on the basis of the finding of a few renal tumors in mice and rats and of stomach papillomas in rats. The fact that methylmercury chloride produced renal adenomas and adenocarcinomas in male mice was considered to provide sufficient evidence for the carcinogenicity of the compound in experimental animals.

Mercury and mercury compounds can be absorbed by various routes. Gastrointestinal absorption of methylmercury compounds is far more efficient than that of mercury following exposure to metallic mercury or inorganic mercury compounds.

Methylmercury compounds produced chromosome effects in vitro and in vivo. The dose of mercuric chloride required to produce sister chromatid exchanges in human lymphocytes in vitro was 5 to 25 times higher than that needed for methylmercury chloride.

The overall evaluation of the working group was that methylmercury compounds are possibly carcinogenic to humans (group 2B in the IARC classification), whereas metallic mercury and inorganic mercury compounds could not be classified as to their carcinogenicity to humans (group 3 ).

\section{Exposure in the glass manufacturing industry}

A monograph was prepared on occupational exposures in glass manufacturing because several epidemiologic studies that suggest an increased risk for lung cancer have been reported in the literature. The industry comprises the following five main sectors: flat glass, glass containers and pressed ware, art glass, special glass (eg, optical, ophthalmic, electronic) and fiber glass (which was not considered by the present working group). Glass production has evolved over the thousands of years since it was discovered, and many of the processes are now automated. Modern production of flat glass is the most highly automated, but art glass production still, for the most part, involves blowing by mouth. The basic ingredient of glass is silica, but exposures to lead, arsenic, and other metallic oxides occur, primarily when nonmechanized techniques are used. Other potential exposures in glass manufacturing include asbestos, other metal oxides, and polycyclic aromatic hydrocarbons.

The evidence that favors a causal association between exposures in the glass manufacturing industry and cancer is a reasonably consistent association with lung cancer in all four available cohort studies of workers involved mainly in art and container glass manufacture, a similar, though less consistent, association with lung cancer in three case-referent studies, the finding of a larger lung cancer risk than can reasonably be explained by nonoccupational confounding factors, the presence of human lung carcinogens in some sectors of the glass manufacturing industry, and the finding of an increased risk for cancer of the stomach in several cohort and case-referent studies.

Findings that were considered to limit the interpretation of causality were the poorly characterized, heterogeneous exposures of workers in this industry, which would be likely to result in a weak or null association in some studies, the absence of demonstrated dose-response relationships, the inclusion of workers in other industries in the risk estimates made in some studies, and the relatively few studies available of workers in the glass manufacturing industry.

Although the type of glass industry studied was usually poorly defined, the studies that provided enough information allowed the working group to conclude that the manufacture of art glass, glass containers, and pressed ware entails exposures that are probably carcinogenic to humans (group $2 \mathrm{~A}$ in the IARC classification). Mainly because of a lack of information, occupational exposures in flat-glass and specialty glass manufacture were considered to be unclassifiable as to their carcinogenicity to humans (group 3).

\section{Concluding remarks}

In most developed countries, occupational exposures to the three metals considered and in the glass man- 
ufacturing industry are now considerably lower than they were several decades ago. The evaluations made by working groups convened by IARC serve, however, to underline hazardous exposures that may still exist, especially as new uses are being found for some of the compounds. They serve especially to alert governments in countries where the compounds and industries are not yet regulated so that preventive action can be taken before situations such as those prevalent in the early part of this century occur. The presence of cadmium and mercury as environmental pollutants and the disastrous consequences that have been experienced as a result of such pollution should be considered in conjunction with these evaluations to forestall any further incidents.

\section{List of participants}

\section{Members}

A Aitio, Biomonitoring Laboratory, Institute of Occupational Health, Arinatie 3,00370 Helsinki, Finland

L Alessio, Institute of Occupational Health, Medicina del Lavoro, Piazzale Spedali Civili 1, 25123 Brescia, Italy

O Axelson, Department of Occupational Medicine, University Hospital, 58185 Linköping, Sweden

J Coenen, Institut für Umwelthygiene an der HeinrichHeine-Universität Düsselsdorf, Postfach 103751, 4000 Düsseldorf, Germany

S De Flora, Institute of Hygiene and Preventive Medicine, University of Genoa, via Pastore 1, 16132 Genoa, Italy

P Grandjean, Department of Environmental Medicine, Institute of Community Health, Odense University, Winsløwparken 17, 5000 Odense C, Denmark (Chairman)

U Heinrich, Department of Experimental and Environmental Hygiene, Fraunhofer Institut für Toxikologie und Aerosolforschung, Nikolai-Fuchs-Strasse 1, 3000 Hanover 61 , Germany

JE Huff, Environmental Carcinogenesis Program, National Institute of Environmental Health Sciences, PO Box 12233, Research Triangle Park, NC 27709, USA

M Ikeda, Department of Public Health, Kyoto University Faculty of Medicine, Kyoto 606, Japan

R Kavlock, Developmental Toxicology Division, Health Effects Research Laboratory, US Environmental Protection Agency (MD-71), Research Triangle Park, NC 27711, USA

G Kazantzis, Environmental Geochemistry Research, Royal School of Mines, Imperial College of Science, Technology and Medicine, Prince Consort Road, London W7 2BP, United Kingdom

S Langård, Telemark Central Hospital, Department of Occupational Medicine, Olavsgt 26, 39000 Porsgrunn, Norway

LS Levy, Institute of Occupational Health, University of Birmingham, B 15 2TT, United Kingdom

G Oberdörster, Department of Environmental Medicine, School of Medicine and Dentistry, 575 Elmwood Avenue, Box EHSC, Rochester, NY 14642, USA

S Olin, ILSI Risk Science Institute, 1126 Sixteenth Street NW, Washington DC 20036, USA
NE Pearce, Department of Medicine, Wellington School of Medicine, University of Otago, PO Box 7343, Wellington South, New Zealand

TG Rossman, Institute of Environmental Medicine, New York University Medical Center, Long Meadow Road, Tuxedo, NY 10987, USA

$\mathrm{KH}$ Schaller, Institut für Arbeits- und Sozialmedizin und Poliklinik für Berufskrankheiten der Universität Erlangen-Nürnberg, Schillerstrasse 25/29, 8520 Erlangen, Germany

C Shy, Department of Epidemiology, School of Public Health, University of North Carolina, CB 7400, Chapel Hill, NC 27599, USA

S Skerfving, Department of Occupational and Environmental Medicine, University Hospital, 22185 Lund, Sweden

S Swierenga, Drugs Directorate, Health and Welfare Canada, Tunney's Pasture, Ottawa, Ontario K1A 012, Canada

MJ Thun, American Cancer Society, 1599 Clifton Road NE, Atlanta, GA 30329, USA

MP Waalkes, Laboratory of Comparative Carcinogenesis, National Cancer Institute, Frederick Cancer Research Development Center, Building 538, Room 205E, Frederick, MD 21702, USA

Representatives/Observers

Commission of the European Communities

G Aresini, Health and Safety Directorate, Industrial Medicine and Hygiene Unit, Commission of the European Communities, Bâtiment Jean Monnet, 2920 Luxembourg, Grand Duchy of Luxembourg

Eurométaux (Association européenne des Métaux)

P Kotin, University of Colorado Medical School, Department of Microbiology, Colorado State University, 4505 South Yosemite 330, Denver, CO 80237, USA

International Council on Metals and the Environment

T Sorahan, Department of Public Health and Epidemiology, University of Birmingham, PO Box 363, Edgbaston, Birmingham B15 2TT, United Kingdom

National Center for Toxicological Research

W Allaben, National Center for Toxicological Research, Jefferson, AR 72079-9502, USA

Occupational Safety and Health Administration

PF Infante, Occupational Safety and Health Administration, Room N-3718, US Department of Labor, 200 Constitution Avenue NW, Washington DC 20210, USA

Primary Glass Manufacturers' Confederation

J Blackburn, 40 Carlton Avenue, Upholland, Skelmersdale, Lancs WN8 0AE, United Kingdom

Harri Vainio, MD, Elisabeth Heseltine, MSc, Christiane Partensky, BSc, Julian Wilbourn, BSc

International Agency for Research on Cancer 150 cours Albert Thomas

F-69372 Lyon Cédex 08, France 